Article

\title{
Adsorptive Properties of Poly(1-methylpyrrol- 2-ylsquaraine) Particles for the Removal of Endocrine-Disrupting Chemicals from Aqueous Solutions: Batch and Fixed-Bed Column Studies
}

\author{
Augustine O. Ifelebuegu ${ }^{1, *(D)}$, Habibath T. Salauh ${ }^{1}$, Yihuai Zhang ${ }^{1}$ and Daniel E. Lynch ${ }^{2}$ \\ 1 School of Energy, Construction and Environment, Coventry University, Coventry CV1 5FB, UK; \\ tittysalau@yahoo.com (H.T.S.); ifelechem@gmail.com (Y.Z.) \\ 2 Exilica Limited, The TechnoCentre, Coventry University Technology Park, Puma Way, Coventry CV1 2TT, \\ UK; d.lynch@exilica.co.uk \\ * Correspondence: A.Ifelebuegu@coventry.ac.uk; Tel.: +44-247-765-7690
}

Received: 27 July 2018; Accepted: 31 August 2018; Published: 4 September 2018

\begin{abstract}
The adsorptive properties of poly(1-methylpyrrol-2-ylsquaraine) (PMPS) particles were investigated in batch and column adsorption experiments as alternative adsorbent for the treatment of endocrine-disrupting chemicals in water. The PMPS particles were synthesised by condensing 3,4-dihydroxycyclobut-3-ene-1,2-dione (squaric acid) with 1-methylpyrrole in butanol. The results demonstrated that PMPS particles are effective in the removal of endocrine disrupting chemicals (EDCs) in water with adsorption being more favourable at an acidic $\mathrm{pH}$, and a superior sorption capacity being achieved at $\mathrm{pH}$. The results also showed that the removal of EDCs by the PMPS particles was a complex process involving multiple rate-limiting steps and physicochemical interactions between the EDCs and the particles. Gibbs free energy of $-8.32 \mathrm{~kJ} / \mathrm{mole}$ and $-6.6 \mathrm{~kJ} / \mathrm{mol}$, and enthalpies of $68 \mathrm{~kJ} / \mathrm{mol}$ and $43 \mathrm{~kJ} / \mathrm{mol}$, were achieved for the adsorption E2 and EE2 respectively The removal efficiencies of the EDCs by PMPS particles were comparable to those of activated carbon, and hence can be applied as an alternative adsorbent in water treatment applications.
\end{abstract}

Keywords: adsorption; PMPS particles; EDCs; breakthrough; fixed-bed column

\section{Introduction}

A variety of organic pollutants known as endocrine-disrupting chemicals (EDCs) are detected in both industrial and municipal wastewater, which have given rise to increased concerns about their existence in, and effects on the environment [1-3]. Multiple studies in literature have demonstrated that EDCs pose a significant health and environmental risk to humans and wildlife, due to their various sources and their ability to disrupt vital hormonal systems, even at nanogram levels [4-6]. Steroid hormones are among the most potent EDCs detected in wastewater effluents around the globe. The traditional wastewater treatment processes are usually not effective in the treatment of these EDCs to reduce them to potentially non-effect concentrations [5]. Adsorptions on to various adsorbents have been investigated as options for their removal from wastewater. Powdered and granular activated carbons have been considerably investigated as adsorbents for the treatment of EDCs in water and wastewater [7-10]. Other adsorbents that have been investigated include; carbon nanotubes [11-13], imprinted polymers [14], zeolites [15], and waste tealeaves [2].

Polysquaraines are a class of conjugated polymers that are synthesised by condensing 3,4-dihydroxycyclobut-3-ene-1,2-dione (or squaric acid) with a suitable electron-donating aromatic/heterocyclic ring system with at least two points for attachment to a squarate group [16]. 
Poly (1-methylpyrrol-2-ylsquaraine) (or PMPS) was one of three types of new squaraine compounds that were first reported in 1965 by Triebs and Jacob [17], but its unique particle shape was not reported until 2005 [18]. Extensive elemental metal adsorption studies on PMPS particles, along with physical studies on their internal porous nature, were published in 2016 [19]. They have also been recently reported as humidity sensing materials by Xiao et al., 2018 [20]. In the current study, we investigated the adsorptive properties of PMPS particles as an alternative adsorbent for the removal of steroid hormones in water and wastewater. The effects of experimental parameters on the performance of PMPS and the feasibility of using them in a continuous flow fixed column bed, were evaluated to establish the process parameters that are required for potential full-scale applications.

\section{Material and Methods}

\subsection{Chemicals}

The chemicals used in in this research including estradiol (E2), 17-ethiny estradiol (EE2), HPLC grade methanol and butanol, squaric acid, 1-methylpyrrole were of analytical grade. They were purchased from Sigma Aldrich (Saint-Quentin-Fallavier, UK). E2 and EE2 solutions were made in methanol. The PMPS particles were prepared at Exilica Limited, Coventry, UK.

\subsection{PMPS Particles}

PMPS particles were prepared as previously described [18,19]. Equimolar quantities of squaric acid and 1-methylpyrrole in butanol were refluxed for $18 \mathrm{~h}$ (Figure 1). The as-prepared PMPS particles were then filtered and washed with hot ethyl acetate for $4 \mathrm{~h}$ before drying at $60{ }^{\circ} \mathrm{C}$. The physical properties of the as-prepared PMPS are presented in Table 1.

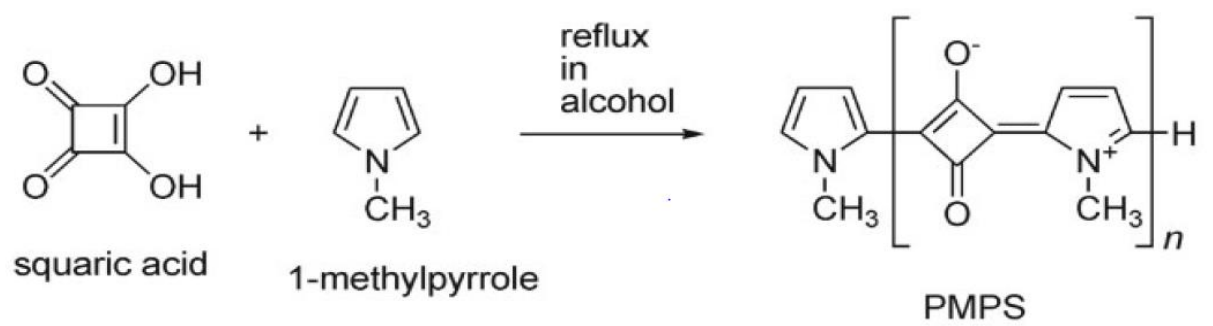

Figure 1. Synthesis of poly (1-methylpyrrol-2-ylsquaraine) (PMPS) particles.

Table 1. Physical characteristics of poly (1-methylpyrrol-2-ylsquaraine) PMPS particles [18,19].

\begin{tabular}{cc}
\hline Physical State & solid \\
Color & black \\
Specific gravity & 1.3 to $1.5 \mathrm{~g} / \mathrm{cm}^{3}$ \\
Average particle size & $1.92 \pm 0.05 \mu \mathrm{m}[21]$ \\
Mean nominal rupture stress & $493 \pm 113 \mathrm{MPa}$ \\
Mean deformation at rupture & $+65 \%$ initial diameter \\
Surface area & $\sim 450 \mathrm{~m}^{2} / \mathrm{g}$ \\
\hline
\end{tabular}

\subsection{Batch Adsorption Experiments}

Batch adsorption isotherm experiments using the bottle point method were carried out at varying concentrations of EDCs $(0.1$ to $2 \mathrm{mg} / \mathrm{L})$ and temperatures $\left(15^{\circ} \mathrm{C}\right.$ and $\left.35^{\circ} \mathrm{C}\right)$. Different weights of the PMPS particles were mixed with $200 \mathrm{~mL}$ of E2 and EE2 in $250 \mathrm{~mL}$ conical flasks. The experiments were conducted in duplicate, and the average values were reported. The $\mathrm{pHs}(2-5,7$, and 8$)$ were varied using dilute $\mathrm{HCl}$ and $\mathrm{NaOH}$ solutions. The mixtures were stirred at a rate of $250 \mathrm{rpm}$ using a magnetic stirrer for $120 \mathrm{~min}$, with regular sampling and analyses at set intervals. The results obtained from the batch experiments were analysed using various kinetic (first and second order) and isotherm (Langmuir, 
Freundlich, and Temkin) models. The thermodynamic parameters were also evaluated from kinetic and thermodynamic data. The amount of EDCs adsorbed was evaluated using Equation (1):

$$
\mathrm{q}_{\mathrm{e}}(\mathrm{mg} / \mathrm{g})=\frac{\mathrm{C}_{\mathrm{o}}-\mathrm{C}_{\mathrm{e}}\left(\frac{\mathrm{mg}}{\mathrm{g}}\right)}{\mathrm{w}(\mathrm{g})} \mathrm{v}(\mathrm{L})
$$

where $C_{o}$ is the initial concentration of the adsorbate and $C_{e}$ is the equilibrium concentration after adsorption, $w$ is the dry weight of adsorbent $(\mathrm{g})$, and $v$ is the volume of aqueous solution $(\mathrm{L})$.

\subsection{Column Adsorption Experiment}

Fixed bed column studies were conducted in a vertical down-flow glass column with internal diameter (d) of $2 \mathrm{~cm}$ and heights varying between $5 \mathrm{~cm}$ and $20 \mathrm{~cm}$, with a feed reservoir of $10 \mathrm{~L}$ at the top of the column. The aqueous solutions of the EDCs were supplied through a peristaltic pump at a constant wetting rate. Treated samples were withdrawn at fixed interval and analysed for residual EDCs that are present. The Adam-Bohart, Thomas, and Yoon-Nelson models were used in predicting the breakthrough curve.

\subsection{Analytical Procedures}

E2 and EE2 were analysed using a Series 1050 HPLC system with a UV detector (HP) at a wavelength of $254 \mathrm{~nm}$, column temperature of $25^{\circ} \mathrm{C}$, and a flow rate of $1.2 \mathrm{~mL} / \mathrm{min}$. The mobile phase was methanol (80\%):water $(20 \%)$ and the analysis was carried out in an isocratic mode. The detailed analytical protocol has been previously described $[22,23]$.

\section{Results and Discussion}

\subsection{Batch Adsorption Experiments}

\subsubsection{Influence of $\mathrm{pH}$ on Adsorptive Capacity of PMPS Particles}

In the adsorption of adsorbates onto the surface of adsorbent materials, the $\mathrm{pH}$ of the solution plays an important role. This is due to the $\mathrm{pH}$ affecting the surface charge of adsorbents, and it can also trigger functional group dissociation on active sites [24]. The effects of $\mathrm{pH}$ on the adsorptive removal of E2 and EE2 were investigated at pH 2 to 8, and a temperature of $25^{\circ} \mathrm{C}$. The results are illustrated in Figure 2. It can be seen that the highest removal of the EDCs was achieved at $\mathrm{pH} 4$. The adsorption capacity increased with $\mathrm{pH}$, and then decreased after 4, showing decreased capacity at neutral to alkaline $\mathrm{pH}$. With the pKa values of E2 and EE2 being 10.4 and 10.7 respectively [10]; at acidic $\mathrm{pHs}$, they both exist predominantly in non-ionic molecular form and therefore are readily adsorbed onto the PMPS particles. However, as the $\mathrm{pH}$ increases, and beyond their dissociation constant (pKa), they become negatively charged, and hence the reduced sorption, due to electrostatic repulsion. Also, as $\mathrm{pH}$ increases, and the hydroxyl ion concentration increases, there is a trigger for the production of aqua-complexes $[25,26]$, which could also contribute to the reduced adsorption capacity at higher $\mathrm{pHs}[10]$.

\subsubsection{Effects of Contact Time and Adsorption Kinetics}

The equilibrium times for the adsorption of the EDCs under consideration were determined at $\mathrm{pH} 4$, for one hour. The results are shown in Figure 3. It can be seen that the adsorption of E2 and EE2 onto the PMPS particles was rapid within the first $10 \mathrm{~min}$ after which the rates slowed, attaining a steady state within the first $20 \mathrm{~min}$, compared to the activated carbon, which has been reported to reach a steady state at 40 to $60 \mathrm{~min}$ for E2 and EE2 [2]. The results demonstrated that the removal rate of $93 \%$ was obtained within $20 \mathrm{~min}$. This is comparable to the performance of activated carbon that was previously reported by Ifelebuegu [10]. Also, with a shorter time to achieve the steady state, PMPS may offer a smaller footprint in potential full-scale applications. 


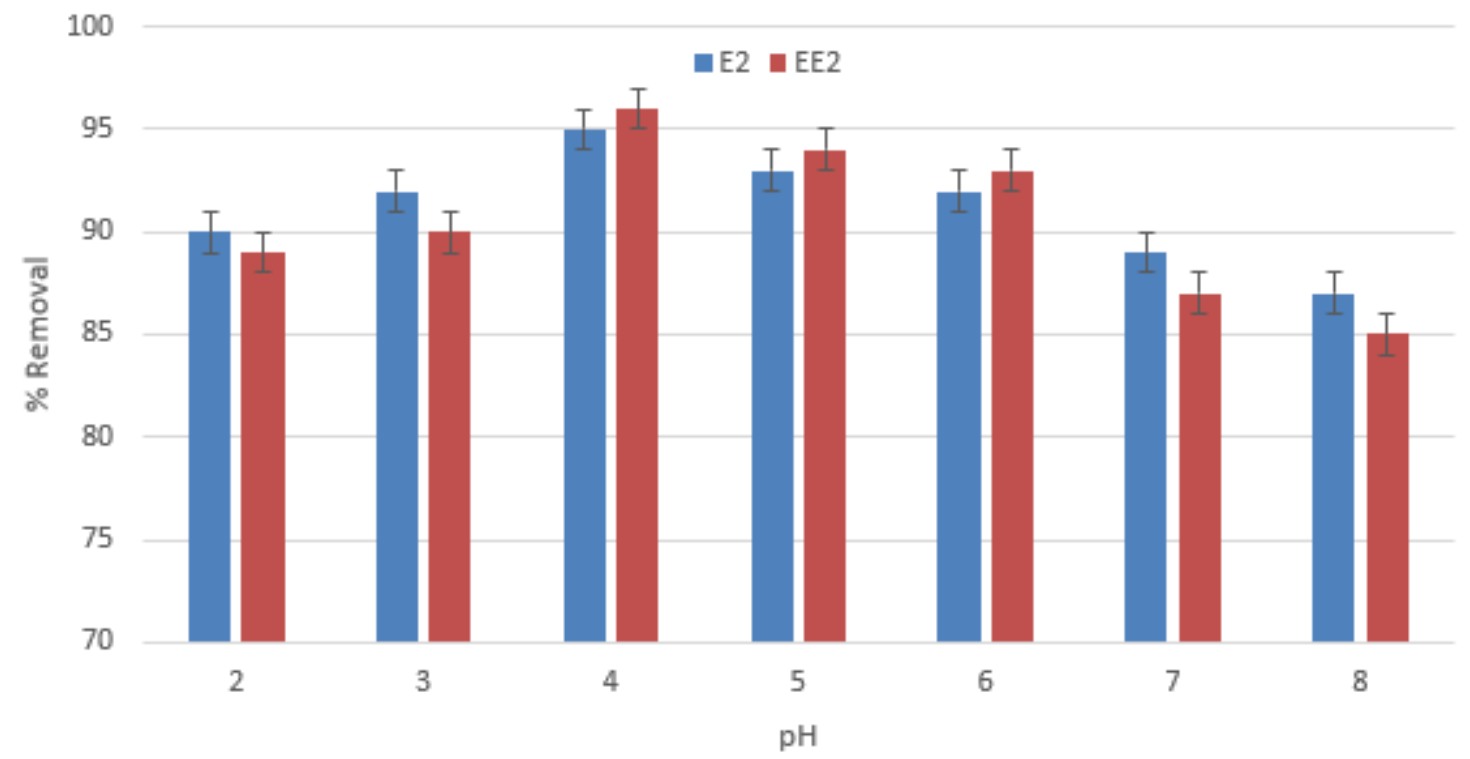

Figure 2. Effect of $\mathrm{pH}$ on the adsorptive removal of estradiol (E2) and 17-ethiny estradiol (EE2) by PMPS particles at a temperature of $25^{\circ} \mathrm{C}$ (Error bars represent the standard deviation of the mean of the duplicates).

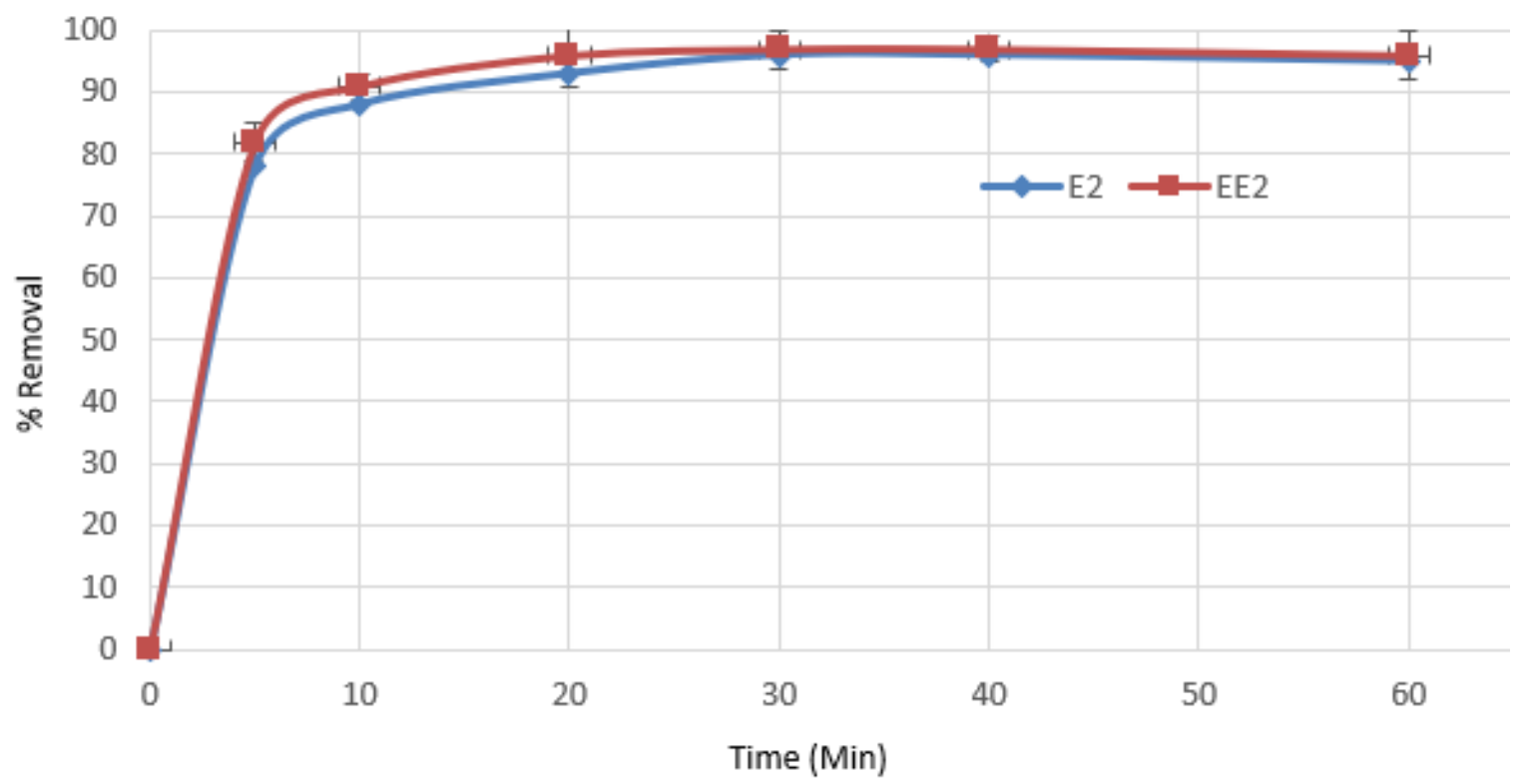

Figure 3. Removal of E2 and EE2 by PMPS particles at varying times and at a temperature of $25^{\circ} \mathrm{C}$ (Error bars represent the standard deviation of the mean of the duplicates).

The kinetics of adsorption is a major consideration in the adsorption system design. It helps in predicting the rate-determining step and helps with obtaining the most optimum operating conditions during the design and optimization of full-scale plants [27]. In the current study, the pseudo-first-order and pseudo-second-order kinetic models were evaluated using the experimental data. The kinetic models for both pseudo-first order and pseudo-second order, as proposed by Lagergren [28] are expressed in Equations (2) and (3) respectively:

$$
\frac{\mathrm{dq}}{\mathrm{dt}}=\mathrm{k}_{1}\left(\mathrm{q}_{\mathrm{e}}-\mathrm{q}\right)
$$




$$
\frac{\mathrm{dq}}{\mathrm{dt}}=\mathrm{k}_{2}\left(\mathrm{q}_{\mathrm{e}}-\mathrm{q}\right)^{2}
$$

where $\mathrm{t}$ is the contact time in $\min , \mathrm{k}_{1}$ is the first-order rate constant $\left(\mathrm{min}^{-1}\right), \mathrm{q}_{\mathrm{e}}$ is the amount of the adsorbate $(\mathrm{mg} / \mathrm{g})$ at equilibrium, and $\mathrm{q}$ is the amount of the adsorbate $(\mathrm{mg} / \mathrm{g})$ at time $\mathrm{t}$. Equations (2) and (3) can also be expressed as Equations (4) and (5) respectively:

$$
\begin{aligned}
& \operatorname{lnC} / C_{\mathrm{o}}=-\mathrm{kt} \\
& \frac{1}{[\mathrm{C}]}-\frac{1}{\left[\mathrm{C}_{\mathrm{o}}\right]}=\mathrm{kt}
\end{aligned}
$$

A plot of $\operatorname{lnC} / C_{o}$ against $t$ gives a linear relationship from which $k_{1}$ is obtained from the slope of the graph. A plot of $1 /[C]-1 /\left[C_{o}\right]$ against $t$ will give a rate constant, $k_{2}\left(\mathrm{Lmg}^{-1} \mathrm{~min}^{-1}\right)$, for the second-order kinetics. The results of the rate constants for E2 and EE2 are presented in Table 2.

The results of the kinetic experiments are presented in Table 2. It can be seen that the experimental data showed a better fit to the pseudo-second-order kinetic model with a higher correlation coefficient $\left(R^{2}=0.996\right.$ for EE2 and 0.993 for E2), compared to the first-order kinetics which also showed a relatively good fit $\left(R^{2}=0.941\right.$ for EE2 and 0.959 for E2). This suggests a complex interaction involving both physical and chemical interactions between the adsorbates and PMPS particles.

Table 2. Rate constants for the kinetic models.

\begin{tabular}{ccccccc}
\hline \multirow{2}{*}{ Adsorbate } & \multicolumn{3}{c}{ Pseudo-First-Order Kinetics } & \multicolumn{3}{c}{ Pseudo-Second-Order Kinetics } \\
\cline { 2 - 7 } & Linear Equation & K & $\mathbf{R}^{\mathbf{2}}$ & Linear Equation & $\mathbf{K}$ & $\mathbf{R}^{\mathbf{2}}$ \\
\hline EE2 & $0.016 \times-0.2366$ & 0.017 & 0.941 & $0.0291 \times-0.072$ & 0.029 & 0.996 \\
E2 & $0.019 \times-0.2207$ & 0.019 & 0.959 & $0.038 \times-0.2084$ & 0.038 & 0.993 \\
\hline
\end{tabular}

\subsubsection{Adsorption Isotherm}

An evaluation of the adsorption isotherms provided insight into how the adsorbate distributed between the solid and aqueous phases. It also helps to model and optimise the design parameters [5,29]. The Langmuir, Freundlich, and Temkin isotherm models were used in the evaluation of the experimental data from this work.

\section{Langmuir Adsorption Isotherm}

The Langmuir isotherm helps to describe the homogeneous adsorption where the adsorption sites exhibit equal affinities for the adsorbate without the movement of the molecules adsorbed in the plane of the adsorbent surface $[30,31]$. The linearised form of the Langmuir isotherm can be expressed as:

$$
\mathrm{q}_{\mathrm{e}}=\frac{\mathrm{Q}_{\mathrm{m}} \mathrm{K}_{\mathrm{L}} \mathrm{C}_{\mathrm{e}}}{1+\mathrm{K}_{\mathrm{L}} \mathrm{C}_{\mathrm{e}}}
$$

where $\mathrm{C}_{\mathrm{e}}(\mathrm{mg} / \mathrm{L})$ is the equilibrium concentration of the EDCs,

$\mathrm{q}_{\mathrm{e}}(\mathrm{mg} / \mathrm{g})$ is the amount of PMPS adsorbed per unit mass,

$\mathrm{Q}_{\mathrm{m}}(\mathrm{mg} / \mathrm{g})$ is the maximum amount of PMPS per unit mass to form a monolayer on the surface,

$\mathrm{K}_{\mathrm{L}}(\mathrm{L} / \mathrm{Mg})$ is the isotherm constant related to the affinity of the binding site.

A plot of $1 / q_{e}$ against $1 / C_{e}$ gives a straight-line graph, with the values of $Q_{m}$ and $K_{L}$ being evaluated from the slope and intercept respectively.

A dimensionless constant or separation factor $\left(R_{L}\right)$ is represented as:

$$
\mathrm{R}_{\mathrm{L}}=\frac{1}{1+\mathrm{K}_{\mathrm{L}} \mathrm{C}_{\mathrm{o}}}
$$


$R_{L}$ describes the favourable nature of the adsorption process; $R_{L}>1$ is unfavourable, $R_{L}=0$ is linear, $0<\mathrm{R}_{\mathrm{L}}<1$ is favourable, and $\mathrm{R}_{\mathrm{L}}=0$ is irreversible [32].

Freundlich Adsorption Isotherm

The Freundlich adsorption isotherm model is an empirical correlation that describes the adsorption on heterogeneous surfaces [33]. The isotherm is expressed as:

$$
\mathrm{Q}_{\mathrm{e}}=\mathrm{K}_{\mathrm{f}} \mathrm{C}_{\mathrm{e}}^{1 / \mathrm{n}} \mathrm{n}>1
$$

The logarithmic form of the Freundlich model is expressed as:

$$
\log Q_{e}=\log _{f}+\frac{1}{n} \log C_{e}
$$

where $\mathrm{K}_{\mathrm{f}}$ is the Freundlich model constant,

$\mathrm{n}$ is a measure of the adsorption intensity,

$\mathrm{C}_{\mathrm{e}}(\mathrm{mg} / \mathrm{L})$ is the adsorbate concentration at equilibrium,

$\mathrm{Q}_{\mathrm{e}}(\mathrm{mg} / \mathrm{g})$ is the amount of PMPS adsorbed per unit mass,

The plot of $\log Q_{e}$ against $\log C_{e}$ gives a straight line and $n$ and $K_{f}$ was evaluated from the slope and intercept respectively.

\section{Temkin Adsorption Isotherm}

The Temkin models is expressed in Equation (10). It assumes that within the adsorption layers, the molecular heat of adsorption tends to decrease linearly with adsorbent coverage, due to the interaction between the adsorbate and the adsorbent [33]. The linearised form of the isotherm is described in Equations (11) and (13):

$$
\begin{gathered}
\mathrm{q}_{\mathrm{e}}=\frac{\mathrm{RT}}{\mathrm{b}} \ln \left(\mathrm{A}_{\mathrm{T}} \mathrm{C}_{\mathrm{e}}\right) \\
\mathrm{q}_{\mathrm{e}}=\frac{\mathrm{RT}}{\mathrm{b}} \ln \mathrm{A}_{\mathrm{T}}+\left[\frac{\mathrm{RT}}{\mathrm{b}}\right] \ln \mathrm{C}_{\mathrm{e}} \\
\mathrm{B}=\frac{\mathrm{RT}}{\mathrm{bT}} \\
\mathrm{q}_{\mathrm{e}}=\mathrm{B} \ln \mathrm{A}_{\mathrm{T}}+\mathrm{BlnC}_{\mathrm{e}}
\end{gathered}
$$

where $A_{T}(L / g)$ is the Temkin binding constant $(L / g), b$ is the Temkin isotherm constant, $R$ is the universal gas constant $(8.314 \mathrm{~J} /(\mathrm{mol} \mathrm{K}))$, $\mathrm{T}$ is temperature at in Kelvin, and $\mathrm{B}(\mathrm{J} / \mathrm{mol})$ is the constant related to heat of sorption. $\mathrm{A}_{\mathrm{T}}$ and $\mathrm{B}$ were evaluated respectively from the intercept and slope of the plot of $\mathrm{q}_{\mathrm{e}}$ against $\ln \mathrm{C}_{\mathrm{e}}$.

Table 3 shows the Langmuir, Freundlich, and Temkin coefficients for single solute adsorption isotherms. The results demonstrated that the Freundlich isotherm achieved the best fit compared to the Langmuir and Temkin isotherms, comparing the correlation coefficients. This suggests a multilayer adsorption. According to Kadirvelu et al., 2003 [34], a value of $n>1$ represents a beneficial adsorption process indicating PMPS particles' affinity for steroid hormones. This also supports a more highly physical interaction between the adsorbates and PMPS. The Langmuir isotherm with relatively good fit also demonstrated that the adsorption of PMPS particles is favorable, with $R_{L}$ values between 0 and 1 . The adsorption of the adsorbates onto the adsorbents are generally very favorable when the value of $R_{L}$ is between 0 and 1 [31,32]. 
Table 3. Isotherm model constants and correction coefficients.

\begin{tabular}{cccccccccc}
\hline \multirow{2}{*}{ Adsorbate } & \multicolumn{3}{c}{ Langmuir } & \multicolumn{3}{c}{ Freundlich } & \multicolumn{3}{c}{ Temkin } \\
\cline { 2 - 10 } & $\mathbf{q}_{\mathbf{m}}$ & $\mathbf{K}_{\mathbf{L}}$ & $\mathbf{R}^{\mathbf{2}}$ & $\mathbf{K}_{\mathbf{f}}$ & $\mathbf{n}$ & $\mathbf{R}^{\mathbf{2}}$ & $\mathbf{A}_{\mathbf{T}}$ & $\mathbf{B}$ & $\mathbf{R}^{\mathbf{2}}$ \\
\hline E2 & 0.313 & 2.80 & 0.977 & 0.287 & 1.59 & 0.995 & 1.386 & 0.2518 & 0.975 \\
EE2 & 0.327 & 2.53 & 0.979 & 0.285 & 1.618 & 0.996 & 1.393 & 0.2517 & 0.981 \\
\hline
\end{tabular}

\subsubsection{Adsorption Thermodynamics}

The temperature effects on the sorption of the EDCs were evaluated at varying temperatures $\left(15,20,25,30\right.$, and $\left.35^{\circ} \mathrm{C}\right)$, with the other experimental variables being kept constant. There was an increase in the retention capacity with increasing temperature, suggesting a possible endothermic reaction and increased desolvation of E2 and EE2 molecules and diffusivity within the PMPS particles. The thermodynamic parameters of the adsorption process (Gibb's free energy $\left(\Delta \mathrm{G}^{0}\right)$, enthalpy $\left(\Delta \mathrm{H}^{0}\right)$, and entropy $\left.\left(\Delta S^{0}\right)\right)$ were evaluated from Equations (14)-(16):

$$
\begin{gathered}
\left(\Delta \mathrm{G}^{0}\right)=-\mathrm{RT} \ln \mathrm{K}_{\mathrm{D}} \\
\left(\Delta \mathrm{G}^{0}\right)=\left(\Delta \mathrm{H}^{0}\right)-\mathrm{T}\left(\Delta \mathrm{S}^{0}\right) \\
-\mathrm{RT} \ln \mathrm{K}_{\mathrm{D}}=\left(\Delta \mathrm{H}^{0}\right)-\mathrm{T}\left(\Delta \mathrm{S}^{0}\right)
\end{gathered}
$$

where $R$ is universal gas constant, $T(K)$ is the Kelvin temperature, and $K_{D}(L / g)$ is the quantity of the EDCs that are adsorbed onto the PMPS. The plot of $\ln K_{\mathrm{D}}$ vs. $1 / \mathrm{T}$ gave a straight line, with $\Delta \mathrm{H}^{0}$ and $\Delta S^{0}$ values being evaluated from the slope and intercept of the graph, respectively. The results are reported in Table 4 . Gibbs free energy values of up to $-20 \mathrm{~kJ} / \mathrm{mol}$ shows adsorptions that are controlled by electrostatic interactions between the PMPS particles and the EDCs $[35,36]$. The values obtained for both E2 and EE2 are less than $10 \mathrm{~kJ} / \mathrm{mol}$, indicating physical adsorption. However, the values of $\Delta \mathrm{H}^{0}$ obtained for E2 $(68 \mathrm{~kJ} / \mathrm{mol})$ and EE2 $(43 \mathrm{~kJ} / \mathrm{mol})$ suggest that the sorption process is chemical in nature. Ifelebuegu, 2011 [5] obtained values of 91 and $95 \mathrm{KJ} / \mathrm{mol}$ for the adsorptions of E2 and EE2 onto granular activated carbon. This supports the previous conclusions from the kinetic and isotherm models that the mechanism of sorption is a combination of physical and chemical interactions between the adsorbates and the PMPS particles. The positive entropy values of E2 $=0.26 \mathrm{~J} / \mathrm{mol} \mathrm{K}$ and $\mathrm{EE} 2=0.17 \mathrm{~J} / \mathrm{mol} \mathrm{K}$, demonstrate an increased randomness that enhanced the retention capacity of the PMPS particles with increasing temperature.

Table 4. Thermodynamic parameters for E2 and EE2 at pH 7.

\begin{tabular}{ccc}
\hline Thermodynamic Parameter & E2 & EE2 \\
\hline Gibbs Free Energy $(\mathrm{kJ} / \mathrm{mol})$ & -8.32 & -6.6 \\
Enthalpy $(\mathrm{kJ} / \mathrm{mol})$ & 68 & 43 \\
Entropy $(\mathrm{J} / \mathrm{mol} \mathrm{K})$ & 0.26 & 0.17 \\
\hline
\end{tabular}

\subsection{Column Studies}

The column tests were carried out using both E2 and EE2. The results obtained were similar; consequently, only those of EE2 have been reported in this section. The breakthrough curve and operational parameters such as bed height, time to breakthrough, and feed flow rates are important parameters in a successful adsorption column design. The breakthrough of EE2 was evaluated at varying bed heights, adsorbate concentrations, and flow rates. 


\subsubsection{Effects of the Operating Parameters on the Breakthrough Curve}

To evaluate the effect of flow rate, the experiments was conducted at varying flowrates of 2.5, 5.5 , and $11.5 \mathrm{~mL} / \mathrm{min}$. Other experimental parameters were left constant $\left(\mathrm{Z}=10 \mathrm{~cm}, \mathrm{C}_{\mathrm{o}}=2 \mathrm{mg} / \mathrm{L}\right)$. The breakthrough curve is shown in Figure 4a. Initially, all the adsorbates were removed as the adsorption proceeded until breakthrough, and there was an abrupt increase in the effluent concentration of EE2. With the increase in flow rate, there was a decrease in the empty bed contact time (EBCT), while the height of the mass transfer zone increased. At a lower flow rate, EE2 had more contact time with the PMPS particles, hence the higher EBCT.

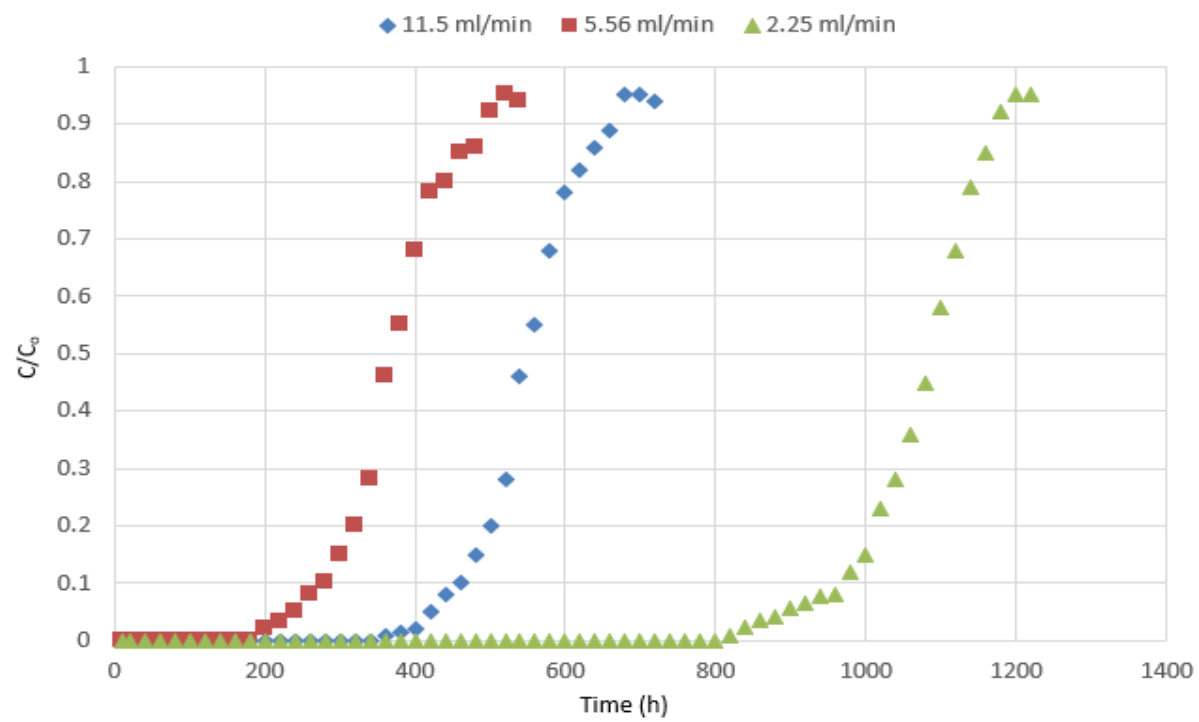

(a)

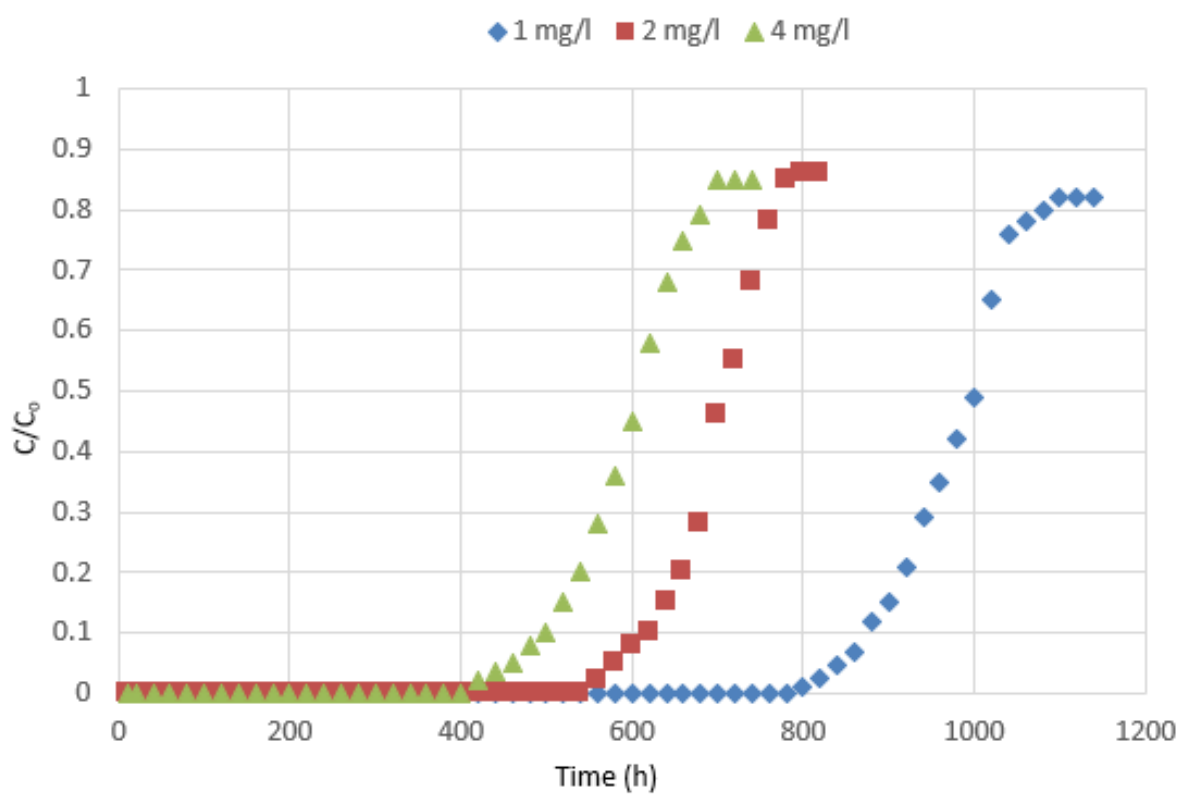

(b)

Figure 4. Cont. 


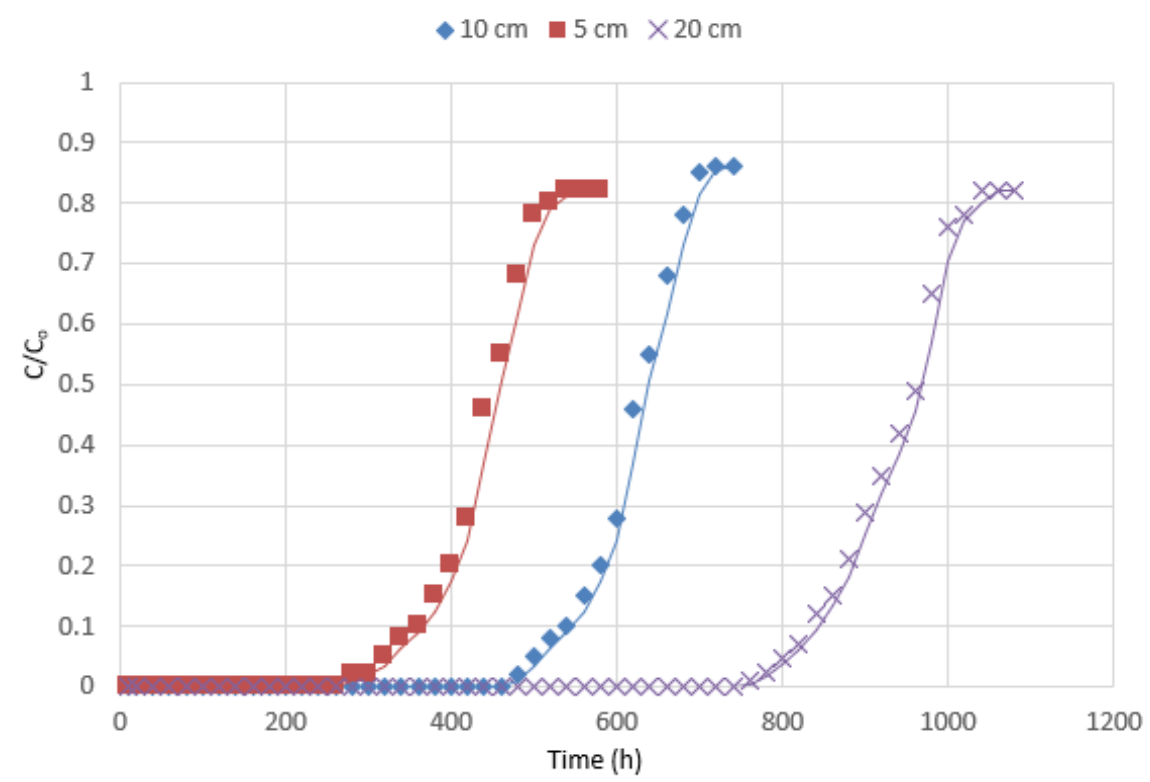

(c)

Figure 4. (a) Breakthrough curve for the adsorption of EE2 by PMPS at varying flow rates $(\mathrm{Z}=10 \mathrm{~cm}$, $\mathrm{C}_{\mathrm{o}}=2 \mathrm{mg} / \mathrm{L}$ ); (b) Breakthrough curve for the adsorption of EE2 by PMPS at varying influent concentrations $(Z=10 \mathrm{~cm}$, flowrate $=5.5 \mathrm{~mL} / \mathrm{min})$; (c) Breakthrough curve for the adsorption of EE2 by PMPS at varying bed heights $\left(C_{o}=2 \mathrm{mg} / \mathrm{L}\right.$, flowrate $\left.=5.5 \mathrm{~mL} / \mathrm{min}\right)$.

The effect of EE2 concentration was also investigate at varying concentrations of 1, 2, and $4 \mathrm{mg} / \mathrm{L}$ $(\mathrm{Z}=10 \mathrm{~cm}$, flowrate $=5.5 \mathrm{~mL} / \mathrm{min}$ ). The breakthrough curves (Figure $4 \mathrm{~b}$ ) demonstrated that with an increase in EE2 concentration, there was a corresponding increase in the steepness of the curves. This is attributed to the relative decrease in the mass transfer zone, as the influent EE2 concentration increased [37]. A higher influent concentration of EE2 made available a higher driving force that enabled the migration process to overcome the mass transfer resistance in the PMPS column, resulting in a higher adsorption of the EE2 in the column. Consequently, the higher exhaustion time demonstrated by the column with a lower EE2 concentration can be attributed to the lower driving force because of the reduced mass transfer resistance [38].

The effect of varying bed height was investigated at $Z=5,10$, and $20 \mathrm{~cm} .\left(C_{o}=2 \mathrm{mg} / \mathrm{L}\right.$, flowrate $=5.5 \mathrm{~mL} / \mathrm{min})$. The throughput volume of the treated solution $\left(\mathrm{V}_{\text {eff }}\right)$ increased as the bed height increased. The slope of the breakthrough curve was less steep with an increasing bed depth (Figure 4c), indicating the presence of an expanded mass transfer zone as the bed depth increased [39]. Yan et al., 2014 [40] reported similar results when the bed height was increased.

\subsubsection{Breakthrough Modelling}

The Adam-Bohart model is normally used for describing the front end of the breakthrough curve, and the model normally assumes that the rate of adsorption is proportional to the sorptive capacity of the adsorbent [41]. The Adam-Bohart expression is given by Equation (17):

$$
\ln \frac{C_{t}}{C_{o}}=k_{A B} C_{o} t-k_{A B} N_{o} \frac{Z}{F}
$$

where, $C_{o}$ and $C_{t}(\mathrm{mg} / \mathrm{L})$ are the influent and effluent PMPS particle concentrations respectively. $k_{A B}$ $(\mathrm{L} / \mathrm{mg} \mathrm{min})$ is the Adam-Bohart constant, $\mathrm{N}_{\mathrm{o}}(\mathrm{mg} / \mathrm{L})$ is the saturation concentration, $\mathrm{F}(\mathrm{cm} / \mathrm{min})$ is the superficial velocity, $\mathrm{Z}(\mathrm{cm})$ is the bed height, and $\mathrm{t}(\mathrm{min})$ is the total flow time. The values of $\mathrm{N}_{\mathrm{o}}$ and $k_{A B}$ were evaluated from the intercept and the slope of the linear plot of $\ln \left(C_{t} / C_{o}\right)$ against time $(t)$ 
for all breakthrough curves. The values are shown in Table 5. It can be seen that $\mathrm{k}_{\mathrm{AB}}$ values increased with increasing EE2 concentrations. However, there was no significant change with increasing bed height. Therefore, it can be inferred that the adsorption of EE2 onto PMPS particles involves several mechanisms, as there was no increase in the mass transfer resistance with increasing bed height.

Table 5. Adam-Bohart parameters at different conditions for the adsorption of EE2 on PMPS particles using a linear regression analysis.

\begin{tabular}{|c|c|c|c|c|c|}
\hline $\mathrm{C}_{\mathrm{o}}\left(\mathrm{mg} \mathrm{L}^{-1}\right)$ & $Z(\mathrm{~cm})$ & $v(\mathrm{~mL} \mathrm{~min}-1)$ & $\mathrm{k}_{\mathrm{AB}}\left(\mathrm{L} \mathrm{mg}^{-1} \min ^{-1}\right) \times 10^{-3}$ & $\mathrm{~N}_{\mathrm{o}}\left(\mathrm{mg} \mathrm{L}^{-1}\right)$ & $\mathbf{R}^{2}$ \\
\hline 1 & 10 & 5.56 & 6.70 & 239 & 0.955 \\
\hline 2 & 10 & 5.56 & 7.55 & 275 & 0.940 \\
\hline 4 & 10 & 5.56 & 6.75 & 377 & 0.899 \\
\hline 2 & 5 & 5.56 & 7.75 & 182 & 0.946 \\
\hline 2 & 20 & 5.56 & 7.55 & 364 & 0.927 \\
\hline 2 & 10 & 2.25 & 7.00 & 170 & 0.988 \\
\hline 2 & 10 & 11.50 & 8.0 & 761 & 0.974 \\
\hline
\end{tabular}

The Adams-Bohart-plots for the removal of EE2 by PMPS particles at $10 \%$ and $50 \%$ breakthrough are shown in Figure 5. At $50 \%$ breakthrough, a plot of $t$ against $Z$ will produce a straight line that passes through the origin. It can be seen that the breakthrough curve did not pass through the origin, an indication that the adsorption of PMPS particles involves a complex process involving multiple rate-limiting steps [42]. This agrees with the finding in the batch adsorption tests.

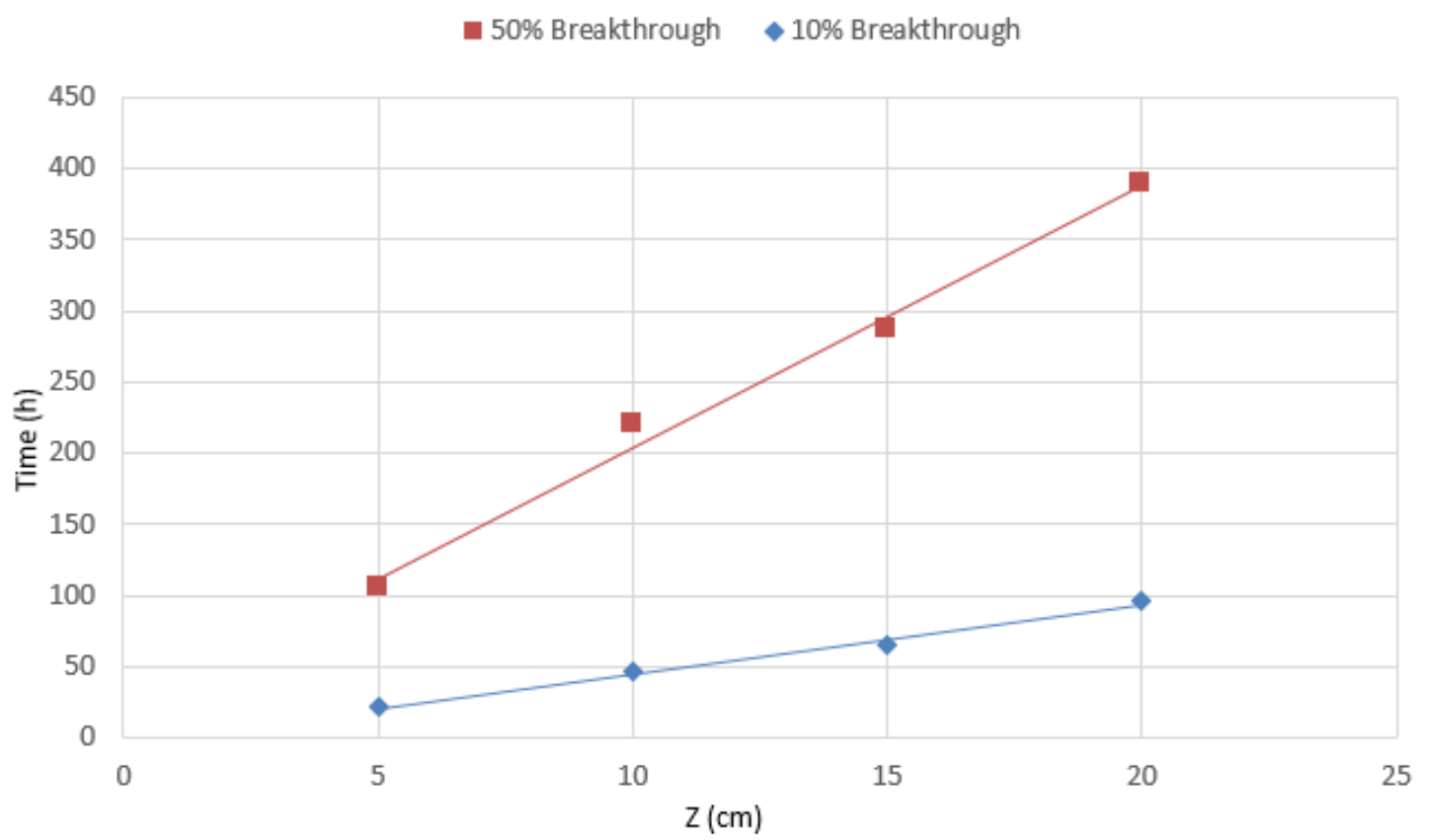

Figure 5. Adam-Bohart plot of EE2 removal by PMPS at 10\% and 50\% breakthrough points.

\section{Thomas Model}

The Thomas model was also used to estimate the adsorptive capacity and to predict the breakthrough curves. It uses the Langmuir isotherm and assumes the absence of axial dispersion with predominating film diffusion [43]. The Thomas Model can be expressed as Equation 18:

$$
\ln \left(\frac{\mathrm{C}_{\mathrm{o}}}{\mathrm{C}_{\mathrm{t}}}-1\right)=\frac{\mathrm{k}_{\mathrm{TH}} \mathrm{q}_{\mathrm{o}} \mathrm{m}}{\mathrm{Q}}-\mathrm{k}_{\mathrm{TH}} \mathrm{C}_{\mathrm{o}} \mathrm{t}
$$


where $\mathrm{k}_{\mathrm{TH}}(\mathrm{mL} / \mathrm{h} / \mathrm{mg})$ is the Thomas kinetic constant, $\mathrm{q}_{\mathrm{o}}(\mathrm{mg} / \mathrm{g})$ is the maximum solid phase concentration, $C_{\mathrm{O}}(\mathrm{mg} / \mathrm{L})$ is the influent EE2 concentration, $\mathrm{Q}(\mathrm{mL} / \mathrm{h})$ is the volumetric flow rate, and $t(h)$ is the total flow time. The values of $k_{T H}$ and $q_{o}$ were obtained from the plot of $\ln \left(C_{o} / C_{t}-1\right)$ against time, using linear regression. The results are reported in Table 6 . It is shown that the Thomas kinetic constant $\left(\mathrm{k}_{\mathrm{TH}}\right)$ and the solid phase concentration of PMPS particles $\left(\mathrm{q}_{\mathrm{o}}\right)$ increased with an increasing influent concentration of EE2. This indicated that the driving force for the adsorption of EE2 onto the PMPS was the concentration gradient [39].

Table 6. Thomas model parameters for EE2 adsorption onto PMPS particles.

\begin{tabular}{cccccc}
\hline$C_{\mathbf{o}}(\mathbf{m g} / \mathbf{L})$ & $\boldsymbol{Z}(\mathbf{c m})$ & $\boldsymbol{v}(\mathbf{m L} / \mathbf{m i n})$ & $\boldsymbol{k}_{\boldsymbol{T H}}(\mathbf{m L} / \mathbf{m i n} \cdot \mathbf{m g}) \times \mathbf{1 0}^{-\mathbf{3}}$ & $\boldsymbol{q}_{\mathbf{o}}(\mathbf{m g} \mathbf{g})$ & $\mathbf{R}^{\mathbf{2}}$ \\
\hline 1 & 10 & 5.56 & 7.50 & 1.67 & 0.956 \\
2 & 10 & 5.56 & 8.70 & 1.86 & 0.966 \\
4 & 10 & 5.56 & 8.85 & 2.50 & 0.930 \\
2 & 5 & 5.56 & 8.25 & 1.31 & 0.956 \\
2 & 20 & 5.56 & 7.70 & 1.39 & 0.930 \\
2 & 10 & 2.25 & 7.40 & 1.11 & 0.987 \\
2 & 10 & 11.50 & 6.6 & 2.56 & 0.923 \\
\hline
\end{tabular}

The Yoon-Nelson Model

The Yoon and Nelson's model assumes that the rate of decrease in the probability of adsorption of each of the adsorbate molecules is directly proportional to the adsorbate molecule adsorption and the breakthrough on the adsorbent [44]. For a single-component system, the model is expressed as Equation (19):

$$
\ln \frac{C_{t}}{C_{o}-C_{t}}=k_{Y N} t-\tau k_{Y N}
$$

where $\mathrm{k}_{\mathrm{YN}}(\mathrm{mL} / \mathrm{min})$ is the Yoon-Nelson constant, and $\tau(\mathrm{min})$ is the time that is required for $50 \%$ breakthrough. $k_{Y N}$ and $\tau$ were evaluated from the plot of $\ln \left[C_{t} /\left(C_{o}-C_{t}\right)\right]$ against $t$ using linear regression. The values obtained are presented in Table 7 . The values of $\mathrm{K}_{\mathrm{YN}}$ increased with increasing influent EE2 concentration and flow rate, while the time to achieve $50 \%$ breakthrough $(\tau)$ being decreased. This is attributed to the increase in the amount of the adsorbate available for adsorption, leading to a shorter breakthrough and exhaustion of the column.

Table 7. Yoon-Nelson parameters for the adsorption of EE2 on PMPS particles.

\begin{tabular}{cccccc}
\hline $\mathbf{C}_{\mathbf{0}}(\mathbf{m g} / \mathbf{L})$ & $\mathbf{Z}(\mathbf{c m})$ & $\boldsymbol{v}(\mathbf{m L} / \mathbf{m i n})$ & $\mathbf{k}_{\mathbf{Y N}}(\mathbf{m L} / \mathbf{m i n})$ & $\boldsymbol{\tau}(\mathbf{m i n})$ & $\mathbf{R}^{\mathbf{2}}$ \\
\hline 1 & 10 & 5.56 & 0.0197 & 999 & 0.956 \\
2 & 10 & 5.56 & 0.0224 & 589 & 0.992 \\
4 & 10 & 5.56 & 0.0259 & 409 & 0.998 \\
2 & 5 & 5.56 & 0.0226 & 456 & 0.989 \\
2 & 20 & 5.56 & 0.0206 & 954 & 0.983 \\
2 & 10 & 2.25 & 0.0201 & 1100 & 0.989 \\
2 & 10 & 11.50 & 0.0213 & 411 & 0.993 \\
\hline
\end{tabular}

\section{Conclusions}

The use of poly(1-methylpyrrol-2-ylsquaraine) particles as an alternative adsorbent for the removal of EDCs from water was investigated using batch and column adsorption experiments. The results of the experiments demonstrated that PMPS particles are effective in the removal of EDCs with the efficiencies of the removal of E2 and EE2 being comparable to those of granular activated carbon. The removal efficiencies were highest at an acidic $\mathrm{pH}$, with the maximum sorption capacity being achieved at $\mathrm{pH}$ 4. The experimental data from both the batch and column adsorption tests showed that the removal mechanism is a complex process involving multiple rate limiting steps and 
physicochemical interactions. A Gibbs free energy of $-8.32 \mathrm{~kJ} / \mathrm{mole}$ and $-6.6 \mathrm{~kJ} / \mathrm{mol}$, and enthalpies of $68 \mathrm{~kJ} / \mathrm{mol}$ and $43 \mathrm{~kJ} / \mathrm{mol}$, were achieved for E2 and EE2 respectively, demonstrating the potential feasibility of deploying PMPS particles as an alternative adsorbent in a full-scale column bed for the removal of EDCs in water and wastewater treatment applications.

Author Contributions: A.O.I. conceived and designed the experiments and prepared the manuscript, D.E.L. synthesized the adsorbent, A.O.I., H.T.S. and Y.Z. carried out the laboratory experiments.

Funding: This research received no external funding

Acknowledgments: The authors thank Exilica Limited for their support in the synthesis of the PMPS adsorbent.

Conflicts of Interest: The authors declare no conflicts of interest

\section{Nomenclature}

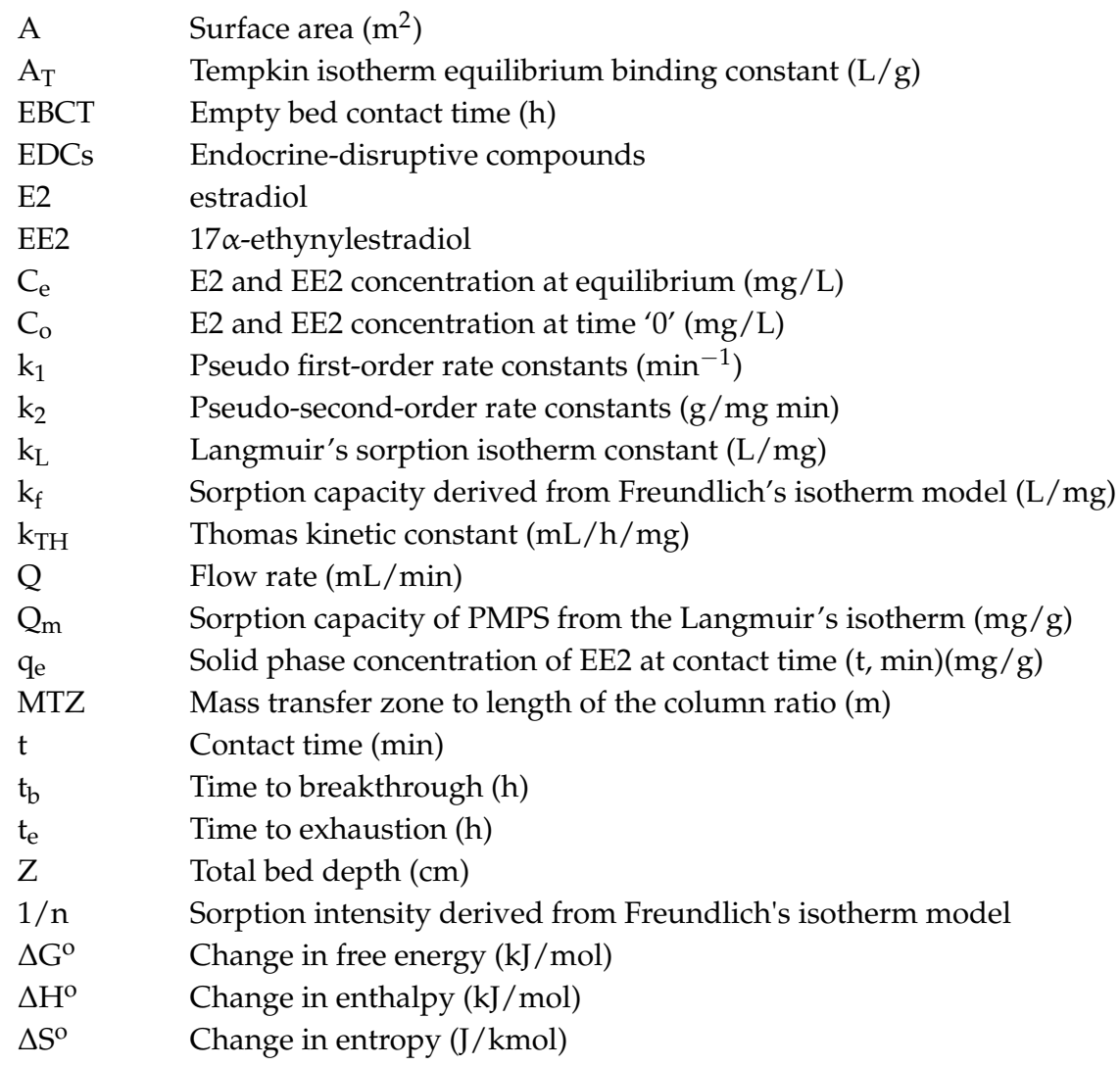

\section{References}

1. Nakada, N.; Tanishima, T.; Shinohara, H.; Kiri, K.; Takada, H. Pharmaceutical chemicals and endocrine disrupters in municipal wastewater in Tokyo and their removal during activated sludge treatment. Water Res. 2006, 40, 3297-3303. [CrossRef] [PubMed]

2. Ifelebuegu, A.O.; Ukpebor, J.E.; Obidiegwu, C.C.; Kwofi, B.C. Comparative potential of black tea leaves waste to granular activated carbon in adsorption of endocrine disrupting compounds from aqueous solution. Glob. J. Environ. Sci. Manag. 2015, 1, 205-214.

3. Ifelebuegu, A.O.; Ukpebor, J.; Nzeribe-Nwedo, B. Mechanistic evaluation and reaction pathway of UV photo-assisted Fenton-like degradation of progesterone in water and wastewater. Int. J. Environ. Sci. Technol. 2016, 13, 2757-2766. [CrossRef]

4. Dalrymple, O.K.; Yeh, D.H.; Trotz, M.A. Removing pharmaceuticals and endocrine-disrupting compounds from wastewater by photocatalysis. J. Chem. Technol. Biotechnol. 2007, 82, 121-134. [CrossRef]

5. Ifelebuegu, A.O. The fate and behaviour of selected endocrine disrupting chemicals in full scale wastewater and sludge treatment unit processes. Int. J. Environ. Sci. Technol. 2011, 8, 245-254. [CrossRef] 
6. Kortenkamp, A. Endocrine disruptors: The burden of endocrine-disrupting chemicals in the USA. Nat. Rev. Endocrinol. 2017, 13, 6-7. [CrossRef] [PubMed]

7. Choi, K.J.; Kim, S.G.; Kim, C.W.; Kim, S.H. Effects of activated carbon types and service life on removal of endocrine disrupting chemicals: Amitrol, nonylphenol, and bisphenol-A. Chemosphere 2005, 58, 1535-1545. [CrossRef] [PubMed]

8. Ifelebuegu, A.O.; Lester, J.N.; Churchley, J.; Cartmell, E. Removal of an endocrine disrupting chemical (17 $\alpha$-ethinyloestradiol) from wastewater effluent by activated carbon adsorption: Effects of activated carbon type and competitive adsorption. Environ. Technol. 2006, 27, 1343-1349. [CrossRef] [PubMed]

9. Kumar, A.K.; Mohan, S.V. Endocrine disruptive synthetic estrogen ( $17 \alpha$-ethynylestradiol) removal from aqueous phase through batch and column sorption studies: Mechanistic and kinetic analysis. Desalination 2011, 276, 66-74. [CrossRef]

10. Ifelebuegu, A.O. Removal of steriod hormones by activated carbon adsorption-Kinetic and thermodynamic studies. J. Environ. Prot. 2012, 3, 469. [CrossRef]

11. Joseph, L.; Zaib, Q.; Khan, I.A.; Berge, N.D.; Park, Y.G.; Saleh, N.B.; Yoon, Y. Removal of bisphenol A and $17 \alpha$-ethinyl estradiol from landfill leachate using single-walled carbon nanotubes. Water Res. 2011, 45, 4056-4068. [CrossRef] [PubMed]

12. Heo, J.; Flora, J.R.; Her, N.; Park, Y.G.; Cho, J.; Son, A.; Yoon, Y. Removal of bisphenol A and 17 $\beta$-estradiol in single walled carbon nanotubes-ultrafiltration (SWNTs-UF) membrane systems. Sep. Purif. Technol. 2012, 90, 39-52. [CrossRef]

13. Zaib, Q.; Khan, I.A.; Saleh, N.B.; Flora, J.R.; Park, Y.G.; Yoon, Y. Removal of bisphenol A and 17 $\beta$-estradiol by single-walled carbon nanotubes in aqueous solution: Adsorption and molecular modeling. Water Air Soil Pollut. 2012, 223, 3281-3293. [CrossRef]

14. Le Noir, M.; Plieva, F.; Hey, T.; Guieysse, B.; Mattiasson, B. Macroporous molecularly imprinted polymer/cryogel composite systems for the removal of endocrine disrupting trace contaminants. J. Chromatogr. A 2007, 1154, 158-164. [CrossRef] [PubMed]

15. Dong, Y.; Wu, D.; Chen, X.; Lin, Y. Adsorption of bisphenol A from water by surfactant-modified zeolite. J. Colloid Interface Sci. 2010, 348, 585-590. [CrossRef] [PubMed]

16. Lynch, D.E. Pyrrolyl Squaraines-Fifty Golden Years. Metals 2015, 5, 1349-1370. [CrossRef]

17. Triebs, A.; Jacob, K. Cyclotrimethine dyes derived from squaric acid. Angew. Chem. Int. Ed. 1965, 4, 694. [CrossRef]

18. Lynch, D.E.; Nawaz, Y.; Bostrom, T. Preparation of sub-micrometer silica shells using poly (1-methylpyrrol-2-ylsquaraine). Langmuir 2005, 21, 6572-6575. [CrossRef] [PubMed]

19. Lynch, D.E.; Bennett, J.B.; Bateman, M.J.; Reeves, C.R. The uptake of metal elements into poly(1-methylpyrrol-2-ylsquaraine) particles and a study of their porosity. Adsorpt. Sci. Technol. 2016, 34, 176-192. [CrossRef]

20. Xiao, X.; Zhang, Q.J.; He, J.H.; Xu, Q.F.; Li, H.; Li, N.J.; Chen, D.Y.; Lu, J.M. Polysquaraines: Novel humidity sensor materials with ultra-high sensitivity and good reversibility. Sens. Actuators B Chem. 2018, 255, 1147-1152. [CrossRef]

21. Begum, S.; Jones, I.P.; Jiao, C.; Lynch, D.E.; Preece, J.A. Characterisation of hollow Russian doll microspheres. J. Mater. Sci. 2010, 45, 3697-3706. [CrossRef]

22. Ifelebuegu, A.O.; Theophilus, S.C.; Bateman, M.J. Mechanistic evaluation of the sorption properties of endocrine disrupting chemicals in sewage sludge biomass. Int. J. Environ. Sci. Technol. 2010, 7, 617-622. [CrossRef]

23. Ifelebuegu, A.O.; Ezenwa, C.P. Removal of endocrine disrupting chemicals in wastewater treatment by Fenton-like oxidation. Water Air Soil Pollut. 2011, 217, 213-220. [CrossRef]

24. Fan, L.; Luo, C.; Sun, M.; Qiu, H.; Li, X. Synthesis of magnetic $\beta$-cyclodextrin-chitosan/graphene oxide as nanoadsorbent and its application in dye adsorption and removal. Colloids Surf. B Biointerfaces 2013, 103, 601-607. [CrossRef] [PubMed]

25. Mohan, S.V.; Shailaja, S.; Krishna, M.R.; Sarma, P.N. Adsorptive removal of phthalate ester (Di-ethyl phthalate) from aqueous phase by activated carbon: A kinetic study. J. Hazard. Mater. 2007, 146, 278-282. [CrossRef] [PubMed]

26. Kumar, A.K.; Mohan, S.V.; Sarma, P.N. Sorptive removal of endocrine-disruptive compound (estriol, E3) from aqueous phase by batch and column studies: Kinetic and mechanistic evaluation. J. Hazard. Mater. 2009, 164, 820-828. [CrossRef] [PubMed] 
27. Kalavathy, M.H.; Karthikeyan, T.; Rajgopal, S.; Miranda, L.R. Kinetic and isotherm studies of Cu (II) adsorption onto $\mathrm{H}_{3} \mathrm{PO}_{4}$-activated rubber wood sawdust. J. Colloid Interface Sci. 2005, 292, 354-362. [CrossRef] [PubMed]

28. Langergren, S. About the theory of so-called adsorption of soluble substances. Sven. Vetenskapsakad. Handlingnaar. 1898, 24, 1-39.

29. Parab, H.; Joshi, S.; Shenoy, N.; Lali, A.; Sarma, U.S.; Sudersanan, M. Determination of kinetic and equilibrium parameters of the batch adsorption of Co (II), Cr (III) and Ni (II) onto coir pith. Process Biochem. 2006, 41, 609-615. [CrossRef]

30. Pérez-Marín, A.; Zapata, V.M.; Ortuno, J.; Aguilar, M.; Sáez, J.; Lloréns, M. Removal of cadmium from aqueous solutions by adsorption onto orange waste. J. Hazard. Mater. 2007, 139, 122-131. [CrossRef] [PubMed]

31. Foo, K.Y.; Hameed, B.H. Insights into the modeling of adsorption isotherm systems. Chem. Eng. J. 2010, 156, 2-10. [CrossRef]

32. Yuan, X.; Xia, W.; An, J.; Yin, J.; Zhou, X.; Yang, W. Kinetic and thermodynamic studies on the phosphate adsorption removal by dolomite mineral. J. Chem. 2015, 2015, 853105. [CrossRef]

33. Dada, A.; Olalekan, A.; Olatunya, A.; Dada, O. Langmuir, Freundlich, Temkin and Dubinin-radushkevich isotherms studies of equilibrium sorption of Zn2 Unto phosphoric acid modified rice husk. J. Appl. Chem. 2012, 3, 38-45.

34. Kadirvelu, K.; Kavipriya, M.; Karthika, C.; Radhika, M.; Vennilamani, N.; Pattabhi, S. Utilization of various agricultural wastes for activated carbon preparation and application for the removal of dyes and metal ions from aqueous solutions. Bioresour. Technol. 2003, 87, 129-132. [CrossRef]

35. Horsfall, M.; Spiff, A.I.; Abia, A.A. Studies on the influence of mercaptoacetic acid (MAA) modification of cassava (Manihot sculenta cranz). waste biomass on the adsorption of $\mathrm{Cu}^{2+}$ and $\mathrm{Cd}^{2+}$ from aqueous solution. Bull. Korean Chem. Soc. 2004, 25, 969-976.

36. Abdel Ghani, N.T.; Elchaghaby, G.A. Influence of operating conditions on the removal of $\mathrm{Cu}, \mathrm{Zn}, \mathrm{Cd}$ and $\mathrm{Pb}$ ion from wastewater by adsorption. Int. J. Environ. Sci. Technol. 2007, 4, 451-456. [CrossRef]

37. Woumfo, E.D.; Siéwé, J.M.; Njopwouo, D. A fixed-bed column for phosphate removal from aqueous solutions using an andosol-bagasse mixture. J. Environ. Manag. 2015, 151, 450-460. [CrossRef] [PubMed]

38. Rout, P.R.; Bhunia, P.; Dash, R.R. Modeling isotherms, kinetics and understanding the mechanism of phosphate adsorption onto a solid waste: ground burnt patties. J. Environ. Chem. Eng. 2014, 2, 1331-1342. [CrossRef]

39. Nur, T.; Loganathan, P.; Nguyen, T.; Vigneswaran, S.; Singh, G.; Kandasamy, J. Batch and column adsorption and desorption of fluoride using hydrous ferric oxide: Solution chemistry and modeling. Chem. Eng. J. 2014, 247, 93-102. [CrossRef]

40. Yan, Y.; Sun, X.; Ma, F.; Li, J.; Shen, J.; Han, W.; Liu, X.; Wang, L. Removal of phosphate from etching wastewater by calcined alkaline residue: Batch and column studies. J. Taiwan Inst. Chem. Eng. 2014, 45, 1709-1716. [CrossRef]

41. Goel, J.; Kadirvelu, K.; Rajagopal, C.; Garg, V.K. Removal of lead (II) by adsorption using treated granular activated carbon: Batch and column studies. J. Hazard. Mater. 2005, 125, 211-220. [CrossRef] [PubMed]

42. Zulfadhly, Z.; Mashitah, M.D.; Bhatia, S. Heavy metals removal in fixed-bed column by the macro fungus Pycnoporus sanguineus. Environ. Pollut. 2001, 112, 463-470. [CrossRef]

43. Ghasemi, M.; Keshtkar, A.R.; Dabbagh, R.; Safdari, S.J. Biosorption of uranium (VI) from aqueous solutions by Ca-pretreated Cystoseira indica alga.Breakthrough curves studies and modeling. J. Hazard. Mater. 2011, 189, 141-149. [CrossRef] [PubMed]

44. Nwabanne, J.; Igbokwe, P. Adsorption performance of packed bed column for the removal of lead (II) using oil palm fibre. Int. J. Appl. Sci. Technol. 2012, 2, 5.

(C) 2018 by the authors. Licensee MDPI, Basel, Switzerland. This article is an open access article distributed under the terms and conditions of the Creative Commons Attribution (CC BY) license (http://creativecommons.org/licenses/by/4.0/). 